\title{
The association between serum apolipoprotein B and fractional exhaled nitric oxide in bronchial asthma patients
}

\author{
Jung Won Heo ${ }^{1 \#}$, Hwa Young Lee ${ }^{2 \#}$, Solji Han ${ }^{3}$, Hye Seon Kang ${ }^{4}$, Soon Seog Kwon ${ }^{4}$, Sook Young Lee \\ ${ }^{1}$ Division of Internal Medicine, Chung-Ang University H.C.S Hyundae Hospital, Namyangju-si, Republic of Korea; ${ }^{2}$ Division of Allergy, \\ Department of Internal Medicine, Seoul St. Mary's Hospital, College of Medicine, The Catholic University of Korea, Seoul, Republic of Korea; \\ ${ }^{3}$ Department of Statistics and Data Science, Yonsei University, Seoul, Republic of Korea; ${ }^{4}$ Division of Pulmonary, Critical Care and Allergy, \\ Department of Internal Medicine, Bucheon St. Mary's Hospital, College of Medicine, The Catholic University of Korea, Seoul, Republic of Korea \\ Contributions: (I) Conception and design: SY Lee; (II) Administrative support: None; (III) Provision of study materials or patients: None; (IV) \\ Collection and assembly of data: JW Heo, HY Lee, HS Kang, SS Kwon; (V) Data analysis and interpretation: Solji Han, HY Lee; (VI) Manuscript \\ writing: All authors; (VII) Final approval of manuscript: All authors. \\ "These authors contributed equally to this work. \\ Correspondence to: Sook Young Lee, MD, PhD. Division of Allergy, Department of Internal Medicine, College of Medicine, The Catholic University \\ of Korea, 222 Banpo-daero, Seocho-gu, Seoul 06591, Republic of Korea. Email: sooklee@catholic.ac.kr.
}

Background: Asthma and lipid metabolism are associated with systemic inflammation. However, the studies about the relationship between lipid profile, fractional exhaled nitric acid (FeNO) and pulmonary function test (PFT) results are currently lacking.

Methods: We enrolled asthma patients who had serum lipid profiles including apolipoprotein levels from March 1, 2019 to December 31, 2019. We classified the asthma patients into two groups according to the diagnosis method: (I) patients who were diagnosed based on clinical symptoms/signs and PFT results and (II) patients diagnosed with clinical symptoms/signs. Clinical characteristics including age, underlying diseases, smoking status, allergy test results and treatment agents were compared between the two groups. The associations between blood cholesterol levels including apolipoprotein and pulmonary functions were analyzed. Moreover, patients were divided into two groups according to the median value of apolipoprotein B (Apo B), and lung function test results were compared between the patients who had high and low Apo B levels.

Results: Among the 167 patients, 93 (55.7\%) were PFT-proven asthma patients. In PFT-proven asthma patients, the levels of total cholesterol (TC) $(\mathrm{r}=0.37, \mathrm{P}=0.03)$, low-density lipoprotein (LDL) $(\mathrm{r}=0.46$, $\mathrm{P}=0.01)$ and Apo B ( $\mathrm{r}=0.38, \mathrm{P}=0.02)$ showed a significant correlation with FeNO, which had no statistical significance in physician-diagnosed asthma group. In multivariate regression analysis, log (FeNO) showed a significant correlation with Apo $\mathrm{B}(\mathrm{P}<0.01)$ after adjustment for presence of PFT-proven asthma $(\mathrm{P}=0.01)$ and current smoking $(\mathrm{P}=0.01)$. Patients with high Apo B levels had a lower post-bronchodilator (BD) forced expiratory volume in 1 second (FEV1)/forced vital capacity (FVC) ratio (69.8 vs. 74.9, $\mathrm{P}=0.02)$ and lower post-BD FEV1 (\%) (77.5 vs. 85.0, $\mathrm{P}=0.04$ ) compared with those showing low Apo B levels.

Conclusions: The levels of Apo B and FeNO had positive correlations and high Apo B levels were associated with severe airflow obstruction and low FEV1 (\%). Apo B could reflect the uncontrolled status of bronchial asthma and poor lung function.

Keywords: Apolipoprotein; respiratory function tests (PFTs); asthma

Submitted Nov 16, 2020. Accepted for publication Apr 29, 2021.

doi: $10.21037 /$ jtd-20-3314

View this article at: https://dx.doi.org/10.21037/jtd-20-3314

(c) Journal of Thoracic Disease. All rights reserved. 


\section{Introduction}

Asthma is one of the most common chronic diseases worldwide. It is associated with various factors, such as genetic susceptibility, host factors (obesity, infection, and allergic sensitization), environmental factors (air pollution, mold, pollen and tobacco smoke) (1). Although most patients diagnosed with asthma receive the treatments available, the disease is not well controlled. Asthma is caused by chronic inflammatory reactions involving the airways. The immune response mediated via T helper 2 (Th2) cells leads to the secretion of cytokines, which triggers airway hyper-responsiveness and allergic airway inflammation (2). Therefore, studies are underway to investigate the pathways and mediators controlling the asthmatic inflammatory responses.

Recent studies have investigated the correlation between asthma and lipid metabolism (3). Asthma and lipid metabolism are associated with systemic inflammation. Asthma and atherosclerosis are characterized by the accumulation of immune cells, activation of mast cells and smooth muscle cells, and increased immunoglobulin E (Ig E) levels $(4,5)$. Activation of the immune system, triggers the release of cytokines, which affects fatty acid oxidation, activating lipoprotein lipase and hepatic lipase, causing dyslipoproteinemia $(6,7)$. It adversely affects the adaptive immune system to mount a Th2 response resulting in asthma and other diseases (8-10).

Lipoprotein plays an important role in serum lipid transportation. Apolipoprotein (Apo) A is a major structural protein component of high-density lipoprotein (HDL), and Apo B is the predominant protein component of lowdensity lipoprotein (LDL) $(11,12)$. Several studies have demonstrated that allergic asthma induces the formation of atherosclerosis in mice (13). Also, some studies showed the relationship between lipoprotein and asthma. Barochia et al. (14) reported that Apo A-I and large HDL particles were positively correlated with forced expiratory volume for 1 second (FEV1) in patients with atopy and asthma. However, serum triglycerides (TG), LDL cholesterol, and Apo B were associated with more severe airflow obstruction. Yao et al. (15) reported that airway hyper-responsiveness and goblet cell hyperplasia increased in Apo E knock-out mice, indicating that Apo E may have a role as a negative regulator of airway hyper-responsiveness and goblet cell hyperplasia.

Fractional exhaled nitric oxide (FeNO) has emerged in recent years as a potentially useful biomarker of Th2 inflammation in the airway (16). Also, it is a non-invasive and simple test that can be used to diagnose asthma eosinophilic inflammation, predict the therapeutic response to steroids, and assess asthma control (17). However, the relationship between lipid profile and FeNO has yet to be analyzed in asthma patients. In this study, we analyzed the relationship between lipid profile and various pulmonary function parameters including FeNO.

We present the following article in accordance with the STROBE reporting checklist (available at https://dx.doi. org/10.21037/jtd-20-3314).

\section{Methods}

\section{Data sources}

We enrolled physician- diagnosed asthma patients whose serum lipid profiles including Apo levels were determined at the Department of Allergy and Pulmonology, Seoul St. Mary's Hospital in the Catholic University of Korea between March 1, 2019 to December 31, 2019. Basic demographic data were collected via retrospective chart review, including age, gender, body mass index (BMI), comorbid conditions, statin use, lipid profile [HDLcholesterol, LDL-cholesterol, TG, total cholesterol (TC), and Apo A and B], pulmonary function parameters, and smoking history including smoking status, pack-years and duration of smoking cessation. We defined ever smokers as those who smoked at least 100 cigarettes during the course of their life. Patients who smoked fewer than 100 cigarettes in their lifetime were defined as a never smokers (18). Patients whose smoking history was unavailable were marked as others. Lung function tests were performed according to the American Thoracic Society/European Respiratory Society standardization guidelines (19). The asthma treatment stages were divided into 5 phases according to the 2020 Global Initiative for Asthma (GINA) guidelines (20). In step 1 of the GINA guidelines, the asneeded low-dose combination inhaled corticosteroid (ICS)formoterol is used, and in step 2, a daily low-dose ICS plus as-needed short-acting beta agonist (SABA), or as-needed low-dose ICS-formoterol is recommended. In step 3, lowdose ICS-long-acting beta agonist (LABA) maintenance plus as-needed SABA, or low-dose ICS-formoterol maintenance and reliever therapy are used, and in step 4, a low-dose ICS-formoterol is used as maintenance and reliever therapy or a medium-dose ICS-LABA maintenance plus as-needed SABA. In step 5, a referral for phenotypic assessment and 
consideration of add-on treatment are recommended. Retrospective chart review was performed by one pulmonology specialist (HY Lee) to maintain consistency of the collected data and data quality was reviewed by statistician from the department of applied statistics (S Han). The study was conducted in accordance with the Declaration of Helsinki (as revised in 2013). This study was approved by the Clinical Research Ethics Committee of the Catholic Medical Center (KC20RISI0489). Because this study was done by retrospective chart review, written informed consent was waived by the Clinical Research Ethics Committee of the Catholic Medical Center.

\section{Asthma diagnostic criteria}

Asthma is characterized by variable symptoms of wheeze, shortness of breath, chest tightness and/or cough and variable expiratory airflow limitations. Both symptoms and airflow limitation characteristically vary over time and in intensity. According to the GINA international guideline, asthma is diagnosed by history of respiratory symptoms and evidence of variable expiratory airflow limitation (20). Thus, asthma is usually diagnosed according to clinical features and pulmonary function tests (PFTs). However, trial of asthma treatment can be performed before the diagnostic lung function tests when the patients have history/examination of asthma diagnosis without alternative diagnosis. Based on this GINA guideline, we classified the asthma patients into two groups according to the diagnosis method: (I) PFT-proven asthma group: patients who were diagnosed based on clinical symptoms/signs and pulmonary function test (PFT) results and (II) physician-diagnosed asthma group: patients diagnosed with clinical symptoms/ signs of asthma. Asthma may involve either a reversible airflow obstruction following administration of an inhaled short-acting $\beta 2$-agonist or, alternatively, airway hyperreactivity in response to methacholine or mannitol bronchial provocation testing. In patients with obstructive spirometry (FEV1/FVC ratio less than 70\%), bronchodilator response (BDR) test is considered to have a positive value when the volume of FEV1 is increased by more than $12 \%$ and $200 \mathrm{~mL}$ or more. In methacholine bronchial provocation test, a $\mathrm{PC}_{20}$ value of $8 \mathrm{mg} / \mathrm{mL}$ or less was considered as a positive test. If FEV1 decreased by more than $15 \%$ after mannitol inhalation, it was considered as a positive result. A FeNO test or exhaled nitric oxide test, in patients with allergic or eosinophilic asthma, is used to determine the degree of lung inflammation and the extent of inflammation suppression using the inhaled steroids (16). In the event of diagnostic uncertainty after initial assessment and either normal or obstructive spirometry with a negative BDR test, an FeNO level of 50 parts per billion (ppb) or more is considered as a positive test (21). Asthma exacerbation is an acute or subacute episode characterized by progressive worsening of symptoms of asthma, including shortness of breath, wheezing, cough, and chest tightness (22). Exacerbation is marked by decreases from baseline in objective measures of pulmonary function, so pulmonary function test was not necessarily performed in patients with asthma exacerbation.

\section{Statistical analysis}

For continuous variables, mean and standard error of the mean (SEM) were calculated for normally distributed variables, whereas medians and the interquartile range (IQR; 25 th-75th) were used for non-normally distributed data. Proportions were used for categorical variables. Analyses of the differences between PFT-proven asthma and physiciandiagnosed asthma group were performed using Student's $t$-test for continuous variables and $\chi^{2}$ test or Fisher's exact test for categorical variables. Odds ratios (ORs) and their $95 \%$ confidence intervals (CIs) were computed. All tests were two-sided, and a $\mathrm{P}$ value $<0.05$ was taken to indicate statistical significance. Correlations between variables were evaluated using Spearman's correlation coefficient. Multiple linear regression models were used to examine the association between cholesterol level and pulmonary function, adjusting for potential confounding variables. Multivariate regression analysis consisted only of variables with $\mathrm{P}$ values less than 0.1 in univariate regression analysis. To compare the pulmonary function test results in the high Apo B and low Apo B expressed patients, Mann-Whitney $\mathrm{U}$ test was performed since the value of two groups categorized according to median values did not follow normal distribution. All statistical analyses were performed using SAS version 9.4 (SAS Institute Inc., Cary, NC, USA).

\section{Results}

The participants' baseline characteristics are presented in Table 1. A total of 167 physician-diagnosed patients were included. Of these patients, $93(55.7 \%)$ were defined as the asthma group based on pulmonary function or acute exacerbation history. In the PFT-proven asthma group, the mean age $(52.2 \pm 18.8$ vs. $58.9 \pm 18.1$ years, $\mathrm{P}=0.02)$ was lower, 
Table 1 Comparison of baseline characteristics between PFT-proven asthma and physician-diagnosed asthma group

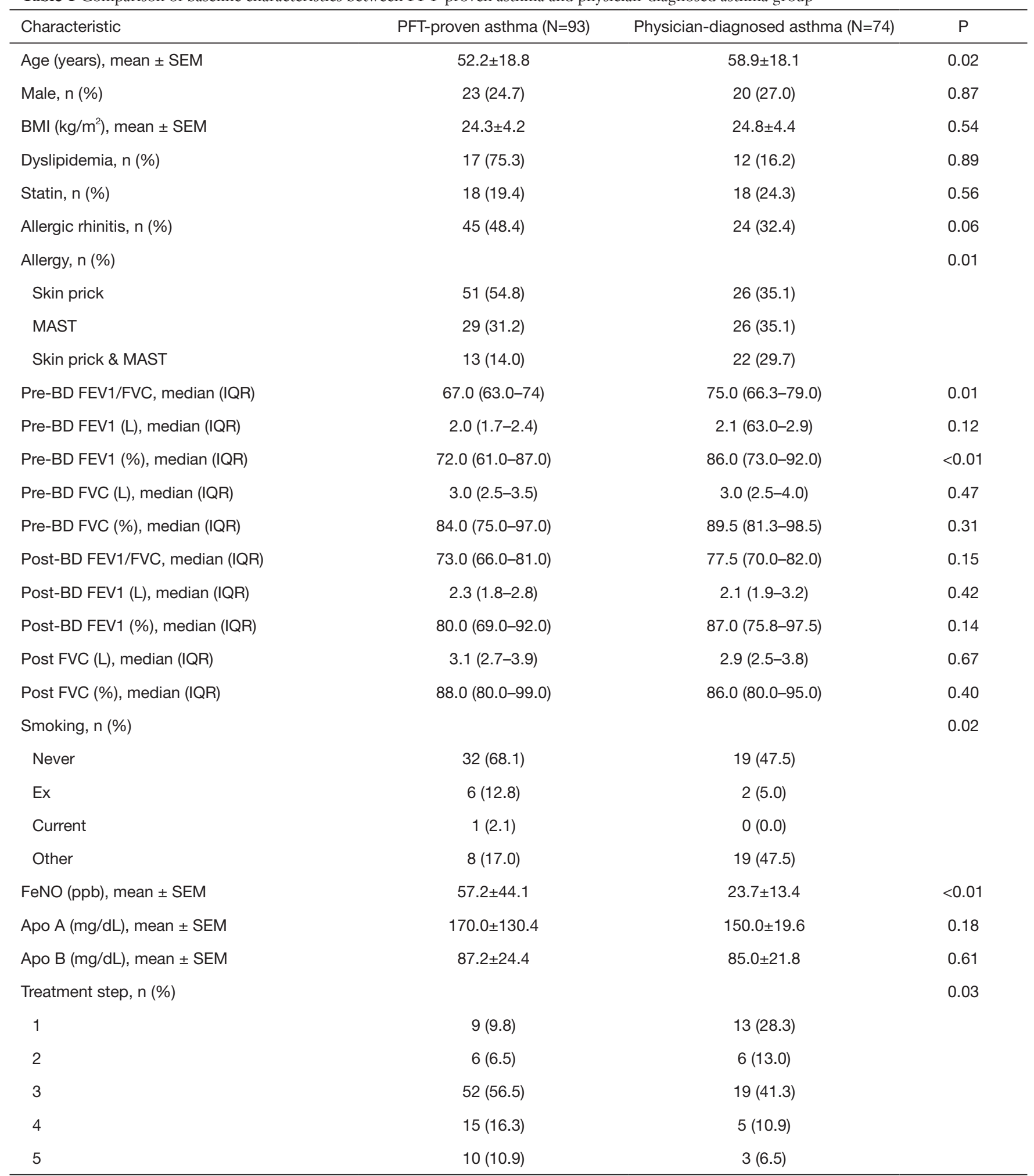

Table 1 (continued) 
Table 1 (continued)

\begin{tabular}{lcc}
\hline Characteristic & PFT-proven asthma (N=93) & Physician-diagnosed asthma (N=74) \\
\hline Treatment agents, $\mathrm{P}(\%)$ & $7(7.5)$ & $5(6.8)$ \\
ICS only & $52(55.9)$ & $22(29.7)$ \\
Low-dose ICS/LABA & $13(14.0)$ & $4(5.4)$ \\
Medium-dose ICS/LABA & $14(15.1)$ & $4(5.4)$ \\
High-dose ICS/LABA & $8(8.6)$ & $3(4.1)$ \\
LAMA & $10(10.8)$ & $11(14.9)$ \\
Systemic steroids & $1(1.1)$ & $001(0)$ \\
Biologics & $53(57.0)$ & $33(44.6)$ \\
LTRA & $5(5.4)$ & $35(47.3)$ \\
None & $320(160-640)$ & $180(0-730)$ \\
Budesonide equivalent (mg), median (IQR) & (10) \\
\hline
\end{tabular}

PFT, pulmonary function test; SEM, standard error of the mean; BMI, body mass index; MAST, multiple allergen simultaneous test; preBD FEV1, pre-bronchodilator forced expiratory volume for 1 second; FVC, forced vital capacity; pre-BD FVC, pre-bronchodilator forced vital capacity; post-BD FEV1, post-bronchodilator forced expiratory volume for 1 second; post-BD FVC, post-bronchodilator forced vital capacity; IQR, interquartile range; FeNO, fractional exhaled nitric oxide; Apo A, apolipoprotein A; Apo B, apolipoprotein B; ICS, inhaled corticosteroid; LABA, long-acting-?2 agonist; LAMA, long-acting muscarinic antagonist; LTRA, leukotriene antagonist.

and at a rate of $68.1 \%$, most patients were never smokers. Also, 51 patients $(54.8 \%)$ tested positive with skin pricks, 29 patients $(31.2 \%)$ were positive for multiple allergen simultaneous test (MAST), and 13 patients (14.0\%) were positive with both test $(\mathrm{P}=0.01)$. In the pulmonary function test, pre-bronchodilator (BD) FEV1/FVC value was lower (67.0\% vs. $75.0 \%, \mathrm{P}=0.01)$ and $\mathrm{FeNO}$ value was higher $(57.2 \pm 44.1$ vs. $23.7 \pm 13.4 \mathrm{ppb}, \mathrm{P}<0.01)$. Among the different treatment categories used, step 3 was the predominant with $56.5 \%$, step 1 constituted $9.8 \%$, step 2 accounted for $6.5 \%$, step 4 was $16.3 \%$, and step 5 was $10.9 \%$. In the PFT-proven asthma group, the step 3-5 treatment was performed most frequently, and in the physician-diagnosed asthma group, the step 1-2 treatment was mainly performed. There was no statistical significance in budesonide equivalence between the groups $(\mathrm{P}<0.11)$.

We performed a correlation analysis of lipid profiles and pulmonary function parameters, including post-BD FVC, FEV1, FEV1/FVC ratio and FeNO (Table 2). Among asthma patients, the level of TC $(r=0.37, P=0.03)$, LDL $(\mathrm{r}=0.46, \mathrm{P}=0.01)$ and Apo $\mathrm{B}(\mathrm{r}=0.38, \mathrm{P}=0.02)$ showed significant correlation with FeNO. However, in physiciandiagnosed asthma patients, there was no statistically significant correlation between Apo B, LDL, TC and FeNO levels. LDL $(r=0.40, P=0.05)$ and $\mathrm{TG}(\mathrm{r}=0.40$, $\mathrm{P}=0.05$ ) showed a positive correlation with FeNO but was not statistically significant in the physician-diagnosed asthma group.

We performed a regression analysis to adjust for potential confounding variables affecting the lung function test results and FeNO. In univariate regression analysis of dependent variables, Apo B showed no statistically significant correlation with post-BD FVC (\%) $(\mathrm{P}=0.15)$ (Table 3). In univariate regression analysis of dependent variable post $\mathrm{BD}$ FEV1 (\%), the correlation with age $(\mathrm{P}=0.05)$, sex $(\mathrm{P}=0.09)$, allergy $(\mathrm{P}=0.04)$, and Apo $\mathrm{B}(\mathrm{P}=0.06)$ showed a $\mathrm{P}$ value less than 0.1 (Table 4). Multivariate regression analysis consisted only of variables with a $\mathrm{P}$ value less than 0.1 in univariate regression analysis. In multivariate regression, post $\mathrm{BD}$ FEV1 (\%) was correlated with age $(\mathrm{P}=0.03)$ and history of allergy $(\mathrm{P}=0.04)$ (Table 4). In the regression analysis of FeNO, there was no normality for the residual variable, so the normality was indicated through $\log$ transformation. The univariate regression analysis of dependent variable $\log (\mathrm{FeNO})$ with, Apo B ( $\mathrm{P}=0.02)$, ex-smoking $(\mathrm{P}=0.08)$ and PFT-proven asthma $(\mathrm{P}<0.01)$ showed a $\mathrm{P}$ value of less than 
Table 2 Spearman correlations between lung function and relevant factors in asthma patients

\begin{tabular}{|c|c|c|c|c|c|c|c|}
\hline Factor & $r / P$ & Post-BD FEV1/FVC & Post-BD FEV1 (L) & Post-BD FEV1 (\%) & Post-BD FEV1 (L) & Post-BD FVC (\%) & $\mathrm{FeNO}$ \\
\hline \multicolumn{8}{|c|}{ PFT-proven asthma group ( $\mathrm{N}=93$ ) } \\
\hline \multirow[t]{2}{*}{ TC } & r & -0.12 & -0.17 & -0.05 & -0.18 & -0.08 & 0.37 \\
\hline & $P$ & 0.51 & 0.34 & 0.75 & 0.30 & 0.64 & 0.03 \\
\hline \multirow[t]{2}{*}{ HDL } & r & 0.28 & -0.02 & 0.11 & -0.26 & -0.02 & -0.14 \\
\hline & $P$ & 0.10 & 0.92 & 0.51 & 0.13 & 0.91 & 0.42 \\
\hline \multirow[t]{2}{*}{ LDL } & r & -0.18 & -0.20 & -0.09 & -0.15 & -0.10 & 0.46 \\
\hline & $P$ & 0.31 & 0.26 & 0.60 & 0.39 & 0.57 & 0.01 \\
\hline \multirow[t]{2}{*}{ TG } & r & -0.49 & -0.14 & -0.44 & 0.12 & -0.32 & 0.12 \\
\hline & $P$ & $<0.01$ & 0.42 & 0.01 & 0.50 & 0.06 & 0.49 \\
\hline \multirow[t]{2}{*}{ Apo A } & r & 0.05 & 0.06 & -0.05 & -0.04 & -0.02 & -0.17 \\
\hline & $P$ & 0.79 & 0.75 & 0.78 & 0.81 & 0.90 & 0.34 \\
\hline \multirow[t]{2}{*}{ Apo B } & r & -0.30 & -0.15 & -0.19 & -0.01 & -0.12 & 0.38 \\
\hline & $P$ & 0.08 & 0.38 & 0.27 & 0.95 & 0.50 & 0.02 \\
\hline \multicolumn{8}{|c|}{ Physician-diagnosed asthma group ( $N=74$ ) } \\
\hline \multirow[t]{2}{*}{ TC } & r & -0.05 & 0.00 & -0.23 & 0.11 & -0.17 & 0.27 \\
\hline & $P$ & 0.81 & 0.99 & 0.26 & 0.60 & 0.42 & 0.20 \\
\hline \multirow[t]{2}{*}{$\mathrm{HDL}$} & r & -0.05 & 0.13 & -0.12 & 0.19 & 0.05 & -0.06 \\
\hline & $P$ & 0.82 & 0.53 & 0.56 & 0.36 & 0.82 & 0.78 \\
\hline \multirow[t]{2}{*}{ LDL } & $r$ & -0.00 & 0.01 & -0.30 & 0.11 & -0.26 & 0.40 \\
\hline & $P$ & 0.99 & 0.95 & 0.15 & 0.59 & 0.21 & 0.05 \\
\hline \multirow[t]{2}{*}{ TG } & $r$ & -0.00 & 0.01 & -0.30 & 0.11 & -0.26 & 0.40 \\
\hline & $P$ & 0.99 & 0.95 & 0.15 & 0.59 & 0.21 & 0.05 \\
\hline \multirow[t]{2}{*}{ Apo A } & $r$ & -0.02 & 0.22 & 0.04 & 0.31 & 0.15 & 0.04 \\
\hline & $P$ & 0.93 & 0.30 & 0.84 & 0.14 & 0.46 & 0.84 \\
\hline \multirow[t]{2}{*}{ Apo B } & $r$ & -0.13 & -0.13 & -0.30 & -0.02 & -0.29 & 0.24 \\
\hline & $P$ & 0.54 & 0.53 & 0.15 & 0.92 & 0.16 & 0.25 \\
\hline
\end{tabular}

Post-BD FEV1, post-bronchodilator forced expiratory volume for 1 second; FVC, forced vital capacity; post-BD FEV1, post-bronchodilator forced expiratory volume for 1 second; post-BD FVC, post-bronchodilator forced vital capacity; TC, total cholesterol; HDL, high-density lipoprotein; LDL, low density lipoprotein; TG, triglyceride; Apo A, apolipoprotein A; Apo B, apolipoprotein B; FeNO, fractional exhaled nitric oxide; PFT, pulmonary function test.

0.1 , and multivariate analysis was performed (Table 5). As a result, the $\log$ distribution of FeNO showed a significant correlation with Apo B $(\mathrm{P}<0.001)$ even after adjustment for PFT-proven asthma $(\mathrm{P}=0.01)$ and current smoking $(\mathrm{P}=0.01)$, which may affect FeNO (Table 5).

We decided to analyze the association of Apo B expression level and lung function parameters. Although there has been no reference to the cutoff level of Apo B in patients with bronchial asthma, the American Diabetes Association and the American College of Cardiology Foundation have suggested a treatment target of $80 \mathrm{mg} / \mathrm{dL}$ Apo B in patients with known cardiovascular disease or with diabetes and another cardiovascular risk factors $(23,24)$. The median value of Apo B was $85 \mathrm{mg} / \mathrm{dL}$ in PFT-proven 
Table 3 Regression analysis for dependent variable post-BD FVC (\%)

\begin{tabular}{|c|c|c|c|c|c|c|}
\hline Variable & \multicolumn{3}{|c|}{ Univariate analysis } & \multicolumn{3}{|c|}{ Multivariate analysis* } \\
\hline Age & -0.17 & 1.06 & 0.01 & -0.13 & 0.07 & 0.06 \\
\hline Sex & -2.74 & 12.37 & 0.28 & - & - & - \\
\hline Statin & -5.43 & 16.16 & 0.05 & -1.75 & 3.78 & 0.64 \\
\hline Apo A & 0.00 & 1.01 & 0.69 & - & - & - \\
\hline Apo B & -0.07 & 1.05 & 0.15 & - & - & - \\
\hline Smoking & & & & - & - & - \\
\hline Never (ref.) & 1.00 & & & & & \\
\hline Dyslipidemia & -5.12 & 18.31 & 0.08 & -2.24 & 3.83 & 0.56 \\
\hline PFT-proven asthma & 2.00 & 10.49 & 0.40 & - & - & - \\
\hline Allergic rhinitis & 4.6 & 9.53 & 0.04 & 2.09 & 2.46 & 0.40 \\
\hline
\end{tabular}

*, clinical parameters which showed $P$ value $<0.1$ at univariate logistic regression were included for multivariate logistic regression. $R^{2}$ $=0.07, P=0.04$. Post-BD FVC, post-bronchodilator forced vital capacity; Apo A, apolipoprotein A; Apo B, apolipoprotein B; PFT, pulmonary function test.

Table 4 Regression analysis for dependent variable post-BD FEV1 (\%)

\begin{tabular}{|c|c|c|c|c|c|c|}
\hline Variable & \multicolumn{3}{|c|}{ Univariate analysis } & \multicolumn{3}{|c|}{ Multivariate analysis ${ }^{*}$} \\
\hline Age & -0.15 & 1.08 & 0.05 & -0.18 & 0.08 & 0.03 \\
\hline Sex & -5.10 & 19.70 & 0.09 & -3.57 & 3.31 & 0.28 \\
\hline Statin & -4.15 & 28.32 & 0.22 & - & - & - \\
\hline Apo A & -0.01 & 1.01 & 0.51 & - & - & - \\
\hline Apo B & -0.12 & 1.06 & 0.06 & -0.11 & 0.06 & 0.10 \\
\hline Smoking & & & & - & - & - \\
\hline Never (ref.) & 1.00 & & & & & \\
\hline Dyslipidemia & -2.18 & 33.11 & 0.54 & - & - & - \\
\hline PFT-proven asthma & -4.15 & 16.25 & 0.14 & - & - & - \\
\hline Allergic rhinitis & 3.03 & 15.12 & 0.27 & - & - & - \\
\hline
\end{tabular}

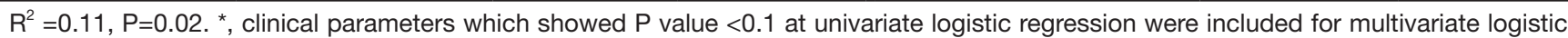
regression. Post-BD FEV1, post-bronchodilator forced expiratory volume for 1 second; Apo A, apolipoprotein A; Apo B, apolipoprotein B; $\mathrm{PFT}$, pulmonary function test. 
Table 5 Regression analysis for dependent variable log (FeNO)

\begin{tabular}{|c|c|c|c|c|c|c|}
\hline Variable & \multicolumn{3}{|c|}{ Univariate analysis } & \multicolumn{3}{|c|}{ Multivariate analysis $^{\dagger}$} \\
\hline Age & -0.004 & 1.01 & 0.46 & - & - & - \\
\hline Sex & 0.05 & 1.23 & 0.80 & - & - & - \\
\hline Statin & -0.15 & 1.36 & 0.62 & - & - & - \\
\hline Apo A & 0.00 & 1.00 & 0.90 & - & - & - \\
\hline Apo B & 0.01 & 1.00 & 0.02 & 0.02 & 0.01 & 0.001 \\
\hline \multicolumn{7}{|l|}{ Smoking } \\
\hline Never (ref.) & 1.00 & & & & & \\
\hline Dyslipidemia & -0.15 & 1.38 & 0.64 & - & - & - \\
\hline PFT-proven asthma & 0.74 & 1.20 & $<0.001$ & 0.60 & 0.21 & 0.01 \\
\hline Allergic rhinitis & 0.14 & 1.22 & 0.50 & - & - & - \\
\hline
\end{tabular}

$\mathrm{R}^{2}=0.46, \mathrm{P}<0.001 .{ }^{\dagger}$, clinical parameters which showed $\mathrm{P}$ value $<0.1$ and at univariate logistic regression and current smoking were included for multivariate logistic regression. FeNO, fractional exhaled nitric oxide; Apo A, apolipoprotein A; Apo B, apolipoprotein B; PFT, pulmonary function test.

asthma group, $39(48.1 \%)$ patients were classified into a high Apo B category and 42 (51.9\%) into a low Apo B category based on the median value $(85 \mathrm{mg} / \mathrm{dL})$. In the Mann-Whitney U test, patients with high Apo B levels had lower post-BD FEV1/FVC ratio (69.8 vs. 74.9, $\mathrm{P}=0.02)$ and a lower post-BD FEV1 (\%) (77.5 vs. 85.0, $\mathrm{P}=0.04)$ than those with low Apo B levels. The difference in FeNO level between high and low Apo B expressing groups was not statistically significant (Table 6).

\section{Discussion}

In our study, the level of FeNO showed a positive association with TC, LDL, and Apo B values only in patients with asthma confirmed via pulmonary function test unlike those in the physician-diagnosed asthma group. The $\log$ distribution of FeNO showed a positive correlation with Apo B even after adjustment for PFT-proven asthma and smoking status, which affect the level of FeNO. In addition, the values significantly correlated with pulmonary function in patients with high Apo B were low post-BD FEV1/FVC ratio and post-BD FEV1 (\%).

Asthma is an inflammatory response mediated by cytokines including interleukin (IL)-4, IL-5 and IL-13, and triggered by Th2 cells (25). Generally, asthma is characterized by chronic airway inflammation, however, recent studies appreciate asthma as a systemic disease. Metabolic syndrome, dyslipidemia and hyperinsulinemia as well as obesity are known to be systemic inflammations, associated with asthma development and progression. (26). The adipose tissue increases pro-inflammatory cytokine response and induces elevated levels of IL-6, tumor necrosis factor- $\alpha$ and systemic inflammation. This inflammation in turn causes macrophage proliferation and lung tissue differentiation resulting in airway inflammation (27). Peng et al. (28) reported that the LDL cholesterol level was higher in the asthma group than in the non-asthma group. In addition, another study reported that asthma was associated with small LDL particles, which were inflammatory mediators (29).

Lipoproteins are complexes composed of specific ratios of lipids and proteins and play an important role in serum lipid transportation. Apo removes cholesterol, TG and phospholipids from the plasma to maintain lipid homeostasis and is used as a structural component of plasma lipoproteins (30). Apo B expressed on the surface of LDL particles acts as a ligand for the cellular LDL 
Table 6 Comparison of lung function test results between the patients with high and low apoprotein B levels

\begin{tabular}{lccc}
\hline Lung function test result & High Apo B (N=39) (median $\pm \mathrm{SEM})$ & Low Apo B (N=42) (median \pm SEM) & P value \\
\hline Pre-BD FEV1/FVC & $66.1 \pm 10.3$ & $68.9 \pm 11.4$ & $74.9 \pm 10.5$ \\
Pre-BD FEV1 (L) & $69.8 \pm 11.1$ & $76.1 \pm 19.7$ & 0.20 \\
Pre-BD FEV1 (\%) & $70.3 \pm 16.4$ & $2.2 \pm 0.7$ & 0.21 \\
Pre-BD FVC (L) & $2.1 \pm 0.7$ & $89.0 \pm 15.9$ & 0.78 \\
Pre-BD FVC (\%) & $83.2 \pm 14.3$ & $74.9 \pm 10.5$ \\
Post-BD FEV1/FVC & $69.8 \pm 11.1$ & $2.5 \pm 0.7$ \\
Post-BD FEV1 (L) & $2.3 \pm 0.7$ & $85.0 \pm 17.0$ \\
Post-BD FEV1 (\%) & $77.5 \pm 14.2$ & $3.4 \pm 0.8$ \\
Post FVC (L) & $3.2 \pm 0.8$ & 9.09 \\
Post FVC (\%) & $86.9 \pm 11.5$ & $9.5 \pm 14.3$ \\
FeNO & $64.4 \pm 45.6$ & $51.7 \pm 43.1$ & 0.23 \\
\hline
\end{tabular}

Pre-BD FEV1/FVC, pre-bronchodilator forced expiratory volume for 1 second/forced vital capacity; pre-BD FEV1, pre-bronchodilator forced expiratory volume for 1 second; pre-BD FVC, pre-bronchodilator forced vital capacity; post-BD FEV1/FVC, pre-bronchodilator forced expiratory volume for 1 second/forced vital capacity; post-BD FEV1, post-bronchodilator forced expiratory volume for 1 second; post-BD FVC, post-bronchodilator forced vital capacity. FeNO, fractional exhaled nitric oxide.

receptor, transporting lipids into the cells. Its expression is related to the concentration of LDL particles. A high blood concentration of Apo B, increases the risk of developing atherosclerosis by forming plaque (31).

There has been little evidence about the association between the blood Apo and airway asthmatic inflammation. However, some studies which evaluated the role of statin use in asthma patients could support the pathogenesis of lipoprotein to asthmatic airway inflammation. The use of statin in asthma patients has been noted for its antiinflammatory effect (32). For example, lovastatin affects differentiation and proliferation of asthmatic bronchial fibroblast and airway smooth muscle cells (33). In addition, it has been reported that simvastatin and atorvastatin reduced inflammatory cells in sputum $(3,34,35)$. Pagovich et al. demonstrated improved lung function in a group using atorvastatin and simvastatin for 4 weeks in a retrospective study $(36,37)$. Also, Cowan et al. showed an increase in peak expiratory flow and FEV1 and a decrease in sputum eosinophils following treatment with simvastatin for 4 weeks in a prospective study $(37,38)$. Based on these studies, lowering blood cholesterol with statins could have improved asthmatic airway inflammation and lung function in asthma patients. In the same way, our positive correlation between Apo B and FeNO could suggest the possible association between dyslipidemia and eosinophilic airway inflammation represented by FeNO.

FeNO has been considered as a non-invasive biomarker of inflammation, especially eosinophilic inflammation $(39,40)$. It is closely related to allergic sensitization (41) and serves as a biomarker of Th2 inflammation in the airways (16). Serum cholesterol enhances eosinophilic inflammation, which is genetically sensitive to atopy, and it causes pro-atopic Th2 immunity and allergic inflammation (10). However, the association between $\mathrm{FeNO}$ value and lipid profile has yet to be reported. The positive correlation of Apo B and FeNO in our study is unique, moreover, could have two clinical implications in asthma patient. First, blood Apo B could be a marker for eosinophilic airway inflammation independent of bronchial hyper-responsiveness and smoking history. Our study revealed positive correlation between LDL and Apo B, a component of LDL after adjustment for pulmonary function test-proven asthma. Among all the asthma patients included in our study, PFT-proven asthma group had positive bronchial hyper-responsiveness in BD response and/or bronchial provocation test. The value of FeNO is known to be elevated in patients with eosinophilic bronchitis with/without bronchial hyper-responsiveness and FeNO is reduced by $20-35 \%$ in smoker $(42,43)$. It is meaningful that our study showed statistical significance in multivariate analysis even after these two factors were adjusted. Second, Apo B might be used as a biomarker 
to predict the therapeutic response to ICS and biologics in asthma patients in addition to FeNO. The FeNO has been shown to be useful in clinically defining asthma and evaluating adherence to ICS treatment $(44,45)$. It can also be used to predict treatment response to biologic agents, exacerbation and loss of control with ICS withdrawal $(21,46)$. Based on positive correlation between Apo B and FeNO, Apo B might be used as a novel biomarker in treatment of bronchial asthma.

In our study, the values of post-BD FEV1/FVC ratio and post-BD FEV1 (\%) were significantly lower in the high Apo B group. In patients with atopy and asthma, one study showed that serum levels of apoA-1 and large HDL particles correlated positively with FEV1. Moreover, serum TG, LDL cholesterol and Apo B level were associated with severe airflow obstruction (14). Serum lipid levels were correlated with FEV1 in more than 30,000 subjects using data from Third National Health and Nutrition Examination Survey (III). In this study, LDL and Apo B also showed a negative correlation with FEV1 (47). The post-BD FEV1/FVC ratio and post-BD FEV1 (\%) are useful indicators for the diagnosis and regulation of asthma, and these studies support the correlation between Apo B, LDL particles, and lung function, consistent with our study.

This study has some limitations. First, it was a retrospective and observational study, potential bias could not be completely eliminated. Second, the sample size was not large and the study was conducted in a single center only, so the results are difficult to generalize. In addition, the positive correlation between $\log (\mathrm{FeNO})$ and Apo B levels in statistical analysis cannot be the causal relationship. Further study is needed to evaluate the exact mechanism. Also, since the blood sampling time was not fixed, it may be related to the fasting time. Despite these limitations, the present study has several strengths. Lung function, bronchial reversibility, hyper-responsiveness and FeNO were measured by skilled technicians. Also, as far as we know, no other study described the association between Apo and FeNO. The most well-known factors affecting FeNO include asthma and smoking $(48,49)$ and our results were significant after adjustment for the confounding factors.

In conclusion, the values of Apo B and FeNO were positively correlated in asthma patients after adjustment of PFT-proven bronchial hyper-responsiveness and smoking history. Moreover, high Apo B was associated with severe airflow obstruction and low FEV1 (\%). Although further studies are needed, Apo B represents a novel biomarker reflecting asthma control status and poor lung function.

\section{Acknowledgments}

Funding: This study was supported by the Research Fund of the Bio \& Medical Technology Development Program of the National Research Foundation (NRF) funded by the Korean government (MSIT) (No. NRF2020M3A9E8024872). The funders had no role in the study design, data collection and analysis, decision to publish, or preparation of the manuscript.

\section{Footnote}

Reporting Checklist: The authors have completed the STROBE reporting checklist. Available at https://dx.doi. org/10.21037/jtd-20-3314

Data Sharing Statement: Available at https://dx.doi. org/10.21037/jtd-20-3314

Peer Review File: Available at https://dx.doi.org/10.21037/ jtd-20-3314

Conflicts of Interest: All authors have completed the ICMJE uniform disclosure form (available at https://dx.doi. org/10.21037/jtd-20-3314). The authors have no conflicts of interest to declare.

Ethical Statement: The authors are accountable for all aspects of the work in ensuring that questions related to the accuracy or integrity of any part of the work are appropriately investigated and resolved. The study was conducted in accordance with the Declaration of Helsinki (as revised in 2013). This study was approved by the Clinical Research Ethics Committee of the Catholic Medical Center (KC20RISI0489). Because this study was done by retrospective chart review, written informed consent was waived by the Clinical Research Ethics Committee of the Catholic Medical Center.

Open Access Statement: This is an Open Access article distributed in accordance with the Creative Commons Attribution-NonCommercial-NoDerivs 4.0 International License (CC BY-NC-ND 4.0), which permits the noncommercial replication and distribution of the article with the strict proviso that no changes or edits are made and the original work is properly cited (including links to both the formal publication through the relevant DOI and the license). See: https://creativecommons.org/licenses/by-nc-nd/4.0/. 


\section{References}

1. Dharmage SC, Perret JL, Custovic A. Epidemiology of Asthma in Children and Adults. Front Pediatr 2019;7:246.

2. Lloyd CM, Hessel EM. Functions of T cells in asthma: more than just Th2 cells. Nat Rev Immunol 2010;10:838-48.

3. Serafino-Agrusa L, Spatafora M, Scichilone N. Asthma and metabolic syndrome: Current knowlege and future perspective. World J Clin Cases 2015;3:285-92.

4. Zhu M, Liang Z, Wang T, et al. Th1/Th2/Th17 cells imbalance in patients with asthma with and without psychological symptoms. Allergy Asthma Proc 2016;37:148-56.

5. Gurgone D, McShane L, McSharry C, et al. Cytokines at the Interplay Between Asthma and Atherosclerosis. Front Pharmacol 2020;11:166.

6. Jukema RA, Ahmed TAN, Tardif JC. Does low-density lipoprotein cholesterol induce inflammation? If so, does it matter? Current insights and future perspectives for novel therapies. BMC Med 2019;17:197.

7. Klingenberg R, Gerdes N, Sparwasser T, et al. Depletion of FOXP3 + regulatory T cells promotes hypercholesterolemia and atherosclerosis. J Clin Invest 2013;123:1323-34.

8. Vinding RK, Stokholm J, Chawes BLK, et al.. Blood lipid levels associate with childhood asthma, airway obstruction, bronchial hyperresponsiveness, and aeroallergen sensitization. J Allergy Clin Immunol 2016;137:68-74.e4.

9. Robertson AK, Zhou X, Strandvik B, et al. Severe hypercholesterolaemia leads to strong Th2 responses to an exogenous antigen. Scand J Immunol 2004;59:285-93.

10. Yeh YF, Huang SL. Enhancing effect of dietary cholesterol and inhibitory effect of pravastatin on allergic pulmonary inflammation. J Biomed Sci 2004;11:599-606.

11. Mangaraj M, Nanda R, Panda S. Apolipoprotein A-I: A Molecule of Diverse Function. Indian J Clin Biochem 2016;31:253-9.

12. Scichilone N, Rizzo M, Benfante A, et al. Serum low density lipoprotein subclasses in asthma. Respir Med 2013;107:1866-72.

13. Gao S, Wang C, Li W, et al. Allergic asthma aggravated atherosclerosis increases cholesterol biosynthesis and foam cell formation in apolipoprotein E-deficient mice. Biochem Biophys Res Commun 2019;519:861-7.

14. Barochia AV, Kaler M, Cuento RA, et al. Serum apolipoprotein A-I and large high-density lipoprotein particles are positively correlated with FEV1 in atopic asthma. Am J Respir Crit Care Med 2015;191:990-1000.

15. Yao X, Remaley AT, Levine SJ. New Kids on the Block: The Emerging Role of Apolipoproteins in the Pathogenesis and Treatment of Asthma. Chest 2011;140:1048-54.

16. de Abreu FC, da Silva Júnior JLR, Rabahi MF. The Fraction Exhaled Nitric Oxide as a Biomarker of Asthma Control. Biomark Insights 2019;14:1177271919826550.

17. Dinh-Xuan AT, Annesi-Maesano I, Berger P, et al. Contribution of exhaled nitric oxide measurement in airway inflammation assessment in asthma. A position paper from the French Speaking Respiratory Society. Rev Mal Respir 2015;32:193-215.

18. Ban WH, Lee JM, Ha JH, et al. Dyspnea as a Prognostic Factor in Patients with Non-Small Cell Lung Cancer. Yonsei Med J 2016;57:1063-9.

19. Standardization of Spirometry, 1994 Update. American Thoracic Society. Am J Respir Crit Care Med 1995;152:1107-36.

20. GINA. Global Strategy for Asthma Management and Prevention. 2020. Available online: https://ginasthma.org/ gina-reports/

21. Dweik RA, Boggs PB, Erzurum SC, et al. An official ATS clinical practice guideline: interpretation of exhaled nitric oxide levels (FENO) for clinical applications. Am J Respir Crit Care Med 2011;184:602-15.

22. Camargo CA, Rachelefsky G, Schatz M. Managing asthma exacerbations in the emergency department: summary of the National Asthma Education And Prevention Program Expert Panel Report 3 guidelines for the management of asthma exacerbations. Proc Am Thorac Soc 2009;6:357-66.

23. Brunzell JD, Davidson M, Furberg CD, et al. Lipoprotein management in patients with cardiometabolic risk: consensus conference report from the American Diabetes Association and the American College of Cardiology Foundation. J Am Coll Cardiol 2008;51:1512-24.

24. Brunzell JD, Davidson M, Furberg CD, et al. Lipoprotein management in patients with cardiometabolic risk: consensus statement from the American Diabetes Association and the American College of Cardiology Foundation. Diabetes Care 2008;31:811-22.

25. Barnes PJ. The cytokine network in asthma and chronic obstructive pulmonary disease. J Clin Invest 2008;118:3546-56.

26. Pite H, Aguiar L, Morello J, et al. Metabolic Dysfunction and Asthma: Current Perspectives. J Asthma Allergy 2020;13:237-47. 
27. Park S, Choi NK, Kim S, et al. The relationship between metabolic syndrome and asthma in the elderly. Sci Rep 2018;8:9378.

28. Peng J, Huang Y. Meta-analysis of the association between asthma and serum levels of high-density lipoprotein cholesterol and low-density lipoprotein cholesterol. Ann Allergy Asthma Immunol 2017;118:61-5.

29. Scichilone N, Rizzo M. A Potential Link between Serum Low-Density Lipoproteins and Asthma. Am J Respir Crit Care Med 2015;192:261-2.

30. Yao X, Gordon EM, Levine SJ. Emerging roles of apolipoprotein $\mathrm{E}$ and apolipoprotein $\mathrm{A}-\mathrm{I}$ in the pathogenesis and treatment of lung disease. Am J Respir Cell Mol Biol 2016;55:159-69.

31. Vrablík M, Ceska R, Horinek A. Major Apolipoprotein B-100 Mutations in Lipoprotein Metabolism and Atherosclerosis. Physiol Res 2001;50:337-43.

32. Maneechotesuwan K, Ekjiratrakul W, Kasetsinsombat $\mathrm{K}$, et al. Statins enhance the anti-inflammatory effects of inhaled corticosteroids in asthmatic patients through increased induction of indoleamine 2, 3-dioxygenase. J Allergy Clin Immunol 2010;126:754-762.e1.

33. Si XB, Zhang S, Huo LY, et al. Statin therapy does not improve lung function in asthma: a meta-analysis of randomized controlled trials. J Int Med Res 2013;41:276-83.

34. Agrawal A, Mabalirajan U, Ahmad T, et al. Emerging Interface Between Metabolic Syndrome and Asthma. Am J Respir Cell Mol Biol 2011;44:270-5.

35. Capra V, Rovati GE. Rosuvastatin Inhibits Human Airway Smooth Muscle Cells Mitogenic Response to Eicosanoid Contractile Agents. Pulm Pharmacol Ther 2014;27:10-6.

36. Pagovich O, Wang E, Lee-Wong M. Statins May Improve Asthma. J Allergy Clin Immunol 2010;125:abstr AB45.

37. Bhattacharjee D, Chogtu B, Magazine R. Statins in Asthma: Potential Beneficial Effects and Limitations. Pulm Med 2015;2015:835204.

38. Cowan DC, Cowan JO, Palmay R, et al. Simvastatin in the treatment of asthma: lack of steroid-sparing effect. Thorax
2010;65:891-6.

39. Pijnenburg MW. The role of FeNO in Predicting Asthma. Front Pediatr 2019;7:41.

40. Pijnenburg MW, De Jongste JC. Exhaled nitric oxide in childhood asthma: a review. Clin Exp Allergy 2008;38:246-59.

41. van Asch CJ, Balemans WA, Rovers MM, et al. Atopic disease and exhaled nitric oxide in an unselected population of young adults. Ann Allergy Asthma Immunol 2008;100:59-65.

42. Taylor DR, Mandhane P, Greene JM, et al. Factors affecting exhaled nitric oxide measurements: the effect of sex. Respir Res 2007;8:82.

43. Malinovschi A, Janson C, Holmkvist T, et al. Effect of smoking on exhaled nitric oxide and flow-independent nitric oxide exchange parameters. Eur Respir J 2006;28:339-45.

44. Khalili B, Boggs PB, Shi R, et al. Discrepancy between clinical asthma control assessment tools and fractional exhaled nitric oxide. Ann Allergy Asthma Immunol 2008;101:124-9.

45. Smith AD, Cowan JO, Brassett KP, et al. Exhaled nitric oxide: a predictor of steroid response. Am J Respir Crit Care Med 2005;172:453-9.

46. Morphew T, Shin HW, Marchese S, et al. Phenotypes favoring fractional exhaled nitric oxide discordance vs guideline-based uncontrolled asthma. Ann Allergy Asthma Immunol 2019;123:193-200.

47. Cirillo DJ, Agrawal Y, Cassano PA. Lipids and pulmonary function in the Third National Health and Nutrition Examination Survey. Am J Epidemiol 2002;155:842-8.

48. Ahovuo-Saloranta A, Csonka P, Lehtimaki L. Basic Characteristics and Clinical Value of FeNO in Smoking Asthmatic-A Systematic Review. J Breath Res 2019;13:034003.

49. Alving K, Weitzberg E, Lundberg JM. Increased amount of nitric oxide in exhaled air of asthmatics. Eur Respir J 1993;6:1368-70.
Cite this article as: Heo JW, Lee HY, Han S, Kang HS, Kwon SS, Lee SY. The association between serum apolipoprotein $\mathrm{B}$ and fractional exhaled nitric oxide in bronchial asthma patients. J Thorac Dis 2021;13(7):4195-4206. doi: $10.21037 /$ jtd-20-3314 